\title{
LA BARRERA HACIA NINGÚN LUGAR: EL CASO DEL PROGRAMA BILATERAL DE ADMINISTRACIÓN DE LA MANO DE OBRA*
}

\author{
ALEJANDRO PORTES**
}

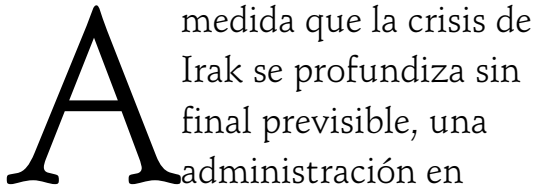

desgracia quizá busque en otra parte una victoria legislativa. La inmigración es una buena candidata, dado que la alianza entre la derecha económica, interesada en mano de obra abundante y la izquierda liberal, interesada en los derechos humanos y en acabar con la explotación de los migrantes, podría realizarse para derrotar a la derecha radical nacionalista. Sobre la mesa ya está una propuesta demócrata, la de Seguridad a través de la Inmigración Regularizada y una Economía Vibrante (Security through Regularized Immigration and a Vibrant Economy, el decreto conocido por las siglas STRIVE del año 2007), cuyos autores fueron los diputados Gutiérrez y Flake; un conjunto paralelo de propuestas recientemente lanzadas por la Casa Blanca. Tanto el conjunto de propuestas como el decreto plantean alguna forma de legalización de la población migrante no autorizada, además de un programa de mano de obra temporal. Se trata de buenos puntos, sin embargo ambas propuestas tienen restricciones y es probable que no puedan ponerse en práctica por razones que presentaremos más adelante.

Hasta el año pasado, los intentos legislativos por sujetar el problema de la inmigración: "nuestras fracturadas fronteras", como lo expresa cotidianamente Lou Dobbs, han estado dominados por el punto de vista de la derecha cultural radical -como ha sido articulado por el

* Escrito especialmente para The American Prospect, abril 2007.

** Universidad de Princeton.

NotA DEL EDITOR: Traducción del inglés por Luis Rodolfo Morán Quiroz. 
profesor de Harvard Samuel

Huntington y se le ha dado expresión popular por Dobbs y otros eruditos de los medios de comunicación- ese punto de vista tiene cuatro partes:

- Los inmigrantes ilegales "invaden" Estados Unidos, contra la voluntad de este país.

- Despojan a los estadounidenses de sus trabajos y disminuyen sus salarios.

- Traen consigo rasgos culturales y lingüísticos que ponen en peligro la cultura estadounidense así como la hegemonía del inglés.

- La mejor manera de lidiar con la inmigración ilegal es suprimirla militarizando la frontera y, si es necesario, elevando una barrera en ella.

Cada uno de estos puntos es incorrecto, de manera demostrable. La voluminosa evidencia al efecto puede sintetizarse como sigue:

- Los migrantes laborales no autorizados no sólo vienen porque quieren sino porque son queridos, si no por todos, al menos por una gran cantidad de patrones y de firmas en las industrias de mano de obra intensiva. Esa demanda -en agricultura, construcción, manufactura de baja tecnología y servicios- no sólo es fuerte sino creciente, impulsada por las fuerzas gemelas de una fecundidad nacional en declive y una fuerza de trabajo estadounidense, que cada vez cuenta con más años de escolaridad. La fecundidad en declive reduce la cantidad de nuevos ingresos en la fuerza de trabajo y el incremento en la escolaridad retrasa el ingreso en el mercado laboral y deriva en una mayor resistencia a aceptar empleos menores de paga reducida. Un reporte reciente de la Oficina de Presupuestos del Congreso considera a este cuello de botella laboral uno de los principales desafíos que confrontará la economía estadounidense en el futuro.

- Los trabajos menores que aceptan los migrantes no autorizados por lo común no son empleos de salario mínimo, porque son tan duros que los patrones se ven obligados a pagar mejores sueldos con el objeto de atraer la demanda. Aun así, pocos estadounidenses están disponibles para cosechar fruta, cavar canales, lavar platos y desempeñar una gran variedad de tareas más humildes. Cuando los migrantes no son localizables para realizar estos trabajos, por lo común van a rogarles. Como ilustración de esta tendencia nacional, nótese el caso de Carolina del Norte, en donde los granjeros recientemente anunciaron la disponibilidad de empleos en la cosecha por $\$ 10$ dólares la hora, con seguro médico y otras prestaciones. Los sembradíos requerían 150,000 trabajadores; hubo 300 solicitudes locales de las cuales 100 se presentaron a trabajar el primer día y ninguno de esos trabajadores terminó la cosecha. La historia se repite de manera rutinaria en época de cosechas y en las zonas de construcción en el país. 
El enunciado de que los

trabajadores manuales migrantes

"despojan de sus empleos a los

estadounidenses" es, en gran

medida, un mito.

- Es verdad que la presencia de trabajadores migrantes hace más lentos los incrementos en los salarios en el sector en que ellos se concentran. En sectores como la construcción y los servicios hoteleros los migrantes se han convertido en los preferidos, frente a los trabajadores nativos por su disposición a desempeñar el mismo empleo por una paga menor o al menos que no aumenta. Sin embargo, considérese el hecho de que si muchas firmas de mano de obra intensiva aumentaran sus salarios lo suficiente para atraer la atención de la decadente mano de obra nacional-digamos a $\$ 25$ dólares la hora por trabajo en la cosecha- tendría que elevar los precios más allá de la tolerancia de los consumidores o acabarían en la quiebra. La continua existencia de una multitud de esas firmas granjas, ranchos, compañías constructoras, restaurantes, negocios de jardinería y decoración panorámica, fábricas de ropa y muchas otras- genera, a su vez, efectos en espiral en forma de empleos en el sector terciario: de oficina, administrativos y de gobierno, mejor pagados que son atractivos para los trabajadores nativos. De esta forma, la fuerza de trabajo migrante acaba por vigorizar las oportunidades de empleo de los trabajadores nativos en varias actividades burocráticas, de supervisión y de regulación.
- Tanto los estudios de corte económico como los de corte sociológico han sido incapaces de mostrar un efecto directo, significativo, de la concentración de migrantes en las tasas de empleo y en los niveles de ingreso de las minorías nacionales. En cambio, los estudios de Bean y Stevens y de Rosenfeld y Tienda, entre otros, apuntan a un patrón de segmentación del mercado de mano de obra en donde los migrantes indocumentados se concentran en la parte baja de los empleos menores y los puestos industriales, mientras que los trabajadores nacionales predominan en el trabajo burocrático y administrativo mejor pagado. El efecto de espiral de la migración, para generar mejores empleos para los trabajadores nativos, se deja completamente a un lado por parte de quienes defienden las restricciones a la inmigración.

- En relación con las fuentes de mano de obra extranjera de bajo costo a las que tienen acceso otras naciones avanzadas como Francia, Alemania y Gran Bretaña, Estados Unidos está realmente en la gloria. México no sólo es su vecino geográfico, sino que es una nación cristiana occidental con numerosos lazos con su vecino del norte. El español es un idioma mundial con múltiples afinidades con el inglés y no existe resistencia alguna por parte de los mexicanos y centroamericanos hacia el aprendizaje del inglés. Los inmigrantes con escasa escolaridad pueden tener dificultad para aprender inglés, pero ciertamente 
se esfuerzan por lograrlo. En su descendencia, sin embargo, el manejo fluido del inglés es casi universal. Efectivamente, lo que se ve en peligro en la segunda generación es su capacidad de hablar español con fluidez. Los estudios de la segunda generación de hispanos muestran que aunque el 98\% manejan con fluidez el inglés, sólo la tercera parte (35\%) conserva la facilidad en el manejo del español.

- El conocimiento del español es un recurso valioso en el mundo moderno, recurso que muchos estadounidenses con alta escolaridad sufren por conseguir. Los niños mexicoamericanos tienen esta habilidad como si fuera derecho de nacimiento y aun así la mayoría la pierde por las presiones hacia la adhesión a una cultura monolingüe. Al contrario de lo que afirma Huntington, no existe un "desafío hispano", que no sea el de que se les conceda el status legal y las oportunidades mínimas para progresar. Los inmigrantes mexicanos se inscriben en grandes cantidades en clases de inglés en California y Texas, en donde existen escuelas con largas listas de espera. Estos inmigrantes nunca se han movilizado políticamente, excepto como reacción a la amenaza inmediata de criminalización y deportación, como sucedió el año pasado a consecuencia de la aprobación de la iniciativa HR4437, la dura iniciativa de Sensenbrenner.

Después de más de tres décadas de lidiar con la inmigración no autorizada como problema policíaco y de gastar miles de millones de dólares en la militarización de la frontera sur, Estados Unidos tiene muy poco qué mostrar como resultado. Presionada por la derecha nacionalista, la patrulla fronteriza ha crecido para convertirse en la rama con mayor dotación de armas del gobierno federal, fuera de las propias fuerzas armadas. Aun así, el flujo no autorizado continúa e incluso se incrementa cada año. En 1996, el economista Thomas Espenshade calculaba que la probabilidad de ser aprehendido durante un intento cualquiera de cruce fronterizo era de $33 \%$. Dado que los migrantes aprehendidos y enviados a México continúan intentándolo una y otra vez, es casi seguro que para la tercera ocasión el intento haya sido exitoso. Según Douglas Massey, la probabilidad de aprehensión de hecho había descendido para 2004 a menos del 15\% en cualquier intento, la razón consistía en que a raíz de la militarización de la frontera el contrabando se ha tornado más profesionalizado. Aún cuando es costoso contratar a un coyote (la tasa corriente es de cerca de $\$ 3,000$ dólares), un grupo de contrabando profesional reduce en gran medida la probabilidad de ser atrapado, en comparación con los cruces sin apoyo en tiempos pasados.

La causa básica, por la cual continúa el flujo a pesar de todos estos esfuerzos policíacos, es la congruencia entre la necesidad de los migrantes mexicanos y centroamericanos de encontrar 
empleo para sobrevivir y mejorar su situación económica y la necesidad de las industrias de mano de obra intensiva en Estados Unidos de encontrar trabajadores motivados. Esta conveniencia es $\tan$ fuerte que desafía todo intento de represión. Si se construye un muro se construirán túneles bajo éste y se encontrarán nuevos cruces, soportando el desierto y el mar si es necesario.

La militarización de la frontera no ha carecido, empero, de consecuencias y por lo general han sido las opuestas a las buscadas: debido a que llegar a Estados Unidos se ha vuelto tan costoso, los migrantes que cruzan la frontera rara vez regresan a sus hogares. En cambio, traen consigo a sus familias en cuanto les es posible. De ahí que la vigilancia de la frontera, que no ha logrado detener el flujo no autorizado, ha triunfado en conservar a estos migrantes embotellados en el lado estadounidense de la frontera. La política ha sido entonces instrumento básico para crear una creciente población de gran tamaño de extranjeros no autorizados en Estados Unidos, exactamente lo opuesto de lo que los defensores de esa política se proponían originalmente.

El fin del viejo patrón cíclico, durante el cual los trabajadores mexicanos cruzaban la frontera por periodos de trabajo de temporada, regresando a sus pueblos y ranchos después de cumplidos estos, significa también que los hijos de esos trabajadores crecen ahora en Estados Unidos. Los niños criados en esas condiciones precarias experimentan grandes dificultades en la escuela y desertan en cantidades significativas, cerrándose así las oportunidades de movilidad ascendente. La discriminación ampliamente difundida, las malas escuelas y la falta de ayuda externa establecieron el escenario para la reproducción de la pobreza por generaciones y para que al menos algunos de estos jóvenes abandonaran el trabajo manual con el objeto de unirse a las pandillas y a la cultura de la droga. El proceso se conoce en la literatura de investigación como "asimilación descendente". Los hijos de los migrantes no autorizados están en riesgo de seguir este camino. Por tanto, la política de la represión de los migrantes no sólo ha creado lo que intentaba prevenir, sino que establece las condiciones para la perpetuación de la pesadilla urbana del crimen, la violencia y las pandillas en las ciudades estadounidenses, esta vez recreada con nuevos protagonistas.

Esta catastrófica situación, resultado directo de una política mal diseñada podría haberse evitado si se entendieran tres simples puntos:

- Estados Unidos necesita y necesitará insumos masivos de fuerza de trabajo manual y México es la fuente natural para cubrir esta necesidad.

- Mantener el carácter cíclico del flujo es vital para el uso apropiado de esta fuerza de trabajo en interés de ambos países.

- Cualquier programa de gobierno que aspire a tener éxito debe buscar administrar este enorme flujo en vez de intentar reprimirlo. 
El estado mexicano ha cortejado con asiduidad al gobierno de Estados Unidos, en su intento de mejorar la situación legal de sus expatriados y de facilitar su retorno. Podría establecerse un acuerdo entre los dos gobiernos en el que, a cambio de concederles un status legal temporal a los trabajadores mexicanos, el gobierno mexicano se hiciera cargo de crear incentivos para el retorno. Un flujo cíclico interesa a México y no sólo a Estados Unidos, por tres razones:

- Evita el despoblamiento de pueblos y regiones enteras, lo que constituye una consecuencia inevitable de la migración familiar permanente.

- Garantiza la continuidad del flujo de remesas, mismo que tiende a agotarse cuando los migrantes llevan a sus familias al otro lado de la frontera.

- Capta los ahorros de los migrantes de retorno, los que pueden invertirse productivamente en la agricultura $y$ en pequeñas empresas urbanas en las comunidades de origen en vez de las de recepción.

Una falacia común, en los círculos de diseño de políticas en Washington, es la suposición de que una vez que los migrantes traspasen la frontera, no se irán jamás. Esta suposición se ve negada por el patrón de migración cíclica que existía antes de la militarización de la frontera y que sigue existiendo entre los migrantes legales en la actualidad. La razón es simple: los hombres y mujeres adultos educados en una lengua y una cultura diferentes por lo general las prefieren y regresarán a ellas, siempre y cuando las condiciones económicas lo permitan. Aún cuando una minoría considerable se establecerá permanentemente en Estados Unidos, la mayoría continuaría con su hogar en México si se le permite.

Reconstruir un patrón de migración cíclica requiere de tres condiciones:

- Garantizar a los migrantes el paso legal por la frontera al regresar de visitar a su familia y sus comunidades de origen.

- Crear instalaciones mínimas de salud y educativas para las familias y los hijos que se quedan.

- Generar oportunidades para la inversión productiva de los ahorros de los migrantes.

El principio operativo consiste en que, para lograr que los migrantes regresen debe haber algo a lo cual regresar. Las comunidades viables en las que las familias puedan irse en paz y los hijos ser educados adecuadamente constituyen una primera condición para que esto suceda. Las oportunidades de inversión para los ahorros de los migrantes de retorno es la segunda de ellas.

El decreto STRIVE de los diputados Gutiérrez y Flake y las propuestas recientes lanzadas por la Casa Blanca son pasos en la dirección correcta, pero tienen cuatro debilidades significativas:

1. Para complacer a la derecha nacionalista están cargadas de 
tantos rasgos represivos y tantas condiciones para la legalización que la tornan costosa, engorrosa y probablemente inoperante. Las medidas represivas -más patrulla fronteriza, más barreras, más vigilancia electrónica- serán costosas y producirán el mismo resultado que las políticas similares del pasado: no detendrán el flujo sino que lo recanalizarán hacia nuevas direcciones. Hacer que la legalización sea compleja y llena de medidas punitivas beneficiará directamente a los contrabandistas y los patrones sin escrúpulos, dado que desanimará a los migrantes no autorizados para seguir adelante.

2. Estas propuestas buscan reformular todo el sistema de inmigración de una vez, sin tener en cuenta que la migración de mano de obra no autorizada es un fenómeno específico con una dinámica bastante distinta de las otras formas de migración. Para resolver la actual situación se requiere una atención concentrada; no su dispersión en los múltiples intríngulis y complejidades del actual sistema de inmigración.

3. Las propuestas abordan el tema de la migración no autorizada con un tono universalista, sin prestar atención al hecho de que se trata, abrumadoramente, de un tema bilateral entre México y Estados Unidos. La gran mayoría de los migrantes no autorizados provienen de México o atraviesan ese país. Cualquier medida de reforma que tenga esperanzas de tener éxito debe privilegiar el carácter bilateral del flujo y requerir una cooperación estrecha entre los dos gobiernos.

4. En buena parte, porque han sido generadas en Washington, estas propuestas parecen asumir que una vez que los migrantes crucen hacia Estados Unidos, ya nunca se irán. Por tanto, no abordan suficientemente la necesidad de restaurar el patrón circular del flujo o proporcionar incentivos significativos para que los migrantes regresen.

En vez de estas propuestas y la actual política ineficaz y costosa de represión en la frontera, un programa bilateral viable de fuerza de trabajo puede construirse a lo largo de estas líneas:

- Todo mexicano adulto con un expediente policial impecable y una constancia de oferta de trabajo en Estados Unidos estaría en condiciones de recibir un permiso temporal de trabajo tras pagar \$2000 dólares en la frontera México-Estados Unidos (aproximadamente dos tercios del precio de la contratación de un contrabandista profesional).

- El permiso sería válido por tres años y renovable por otros tres. Dependerá de que se permanezca con el primer patrón por un mínimo de 90 días. Después de eso, el migrante estará en libertad de buscar un empleo alternativo.

- Los trabajadores migrantes temporales tendrán los mismos derechos que los trabajadores nativos, incluido el derecho a unirse a los sindicatos y a votar en 
los mismos. Los impuestos a la renta y de seguridad social se deducirán de sus cheques de pago.

- Al regresar de forma permanente a México, el migrante recibirá la mitad de su cuota de ingreso (\$1000 dólares), más todos los pagos de seguridad social acumulados, pagaderos a través de un banco mexicano.

- Los migrantes que deseen establecerse permanentemente en Estados Unidos, después de seis años, como trabajadores temporales serán elegibles para hacerlo a través de una provisión especial de la ley de inmigración, una vez comprobado que tienen un expediente policíaco sin mancha, un trabajo estable y una cuenta bancaria considerable en un banco estadounidense. No recibirán el reembolso de la cuota de entrada o el pago acumulado de la seguridad social dado que no se espera que los necesiten para el retiro en Estados Unidos. No obstante, su solicitud de residencia permanente recibirá un tratamiento expedito.

- Los migrantes no autorizados que ya se encuentren en Estados Unidos serán los primeros en la fila para obtener permisos de trabajo temporal, una vez comprobado que tengan un expediente policial sin mancha y un empleo comprobable. A todos los mexicanos no autorizados que se presenten para el efecto se les dará un status protegido temporal mientras se procesan sus permisos. Quienes puedan mostrar que han vivido al menos tres años en el país serán candidatos a la residencia permanente tras otros tres años como trabajadores temporales legales.

- El programa estará limitado inicialmente a un millón anual de nuevos ingresos (un estimado conservador del actual flujo no autorizado). La cifra se ajustará periódicamente en consulta con las asociaciones de patrones, sindicatos y con el gobierno mexicano.

El Estado mexicano debe comprometer su apoyo a este programa binacional de fuerza de trabajo en los siguientes términos:

- Acelerar las inversiones sociales en las áreas de origen de los migrantes, para garantizar adecuadas instalaciones de salud y educación para las familias y los hijos que se quedan.

- Continuar el actual programa Tres por Uno a través del cual cada dólar remitido por las organizaciones migrantes en Estados Unidos, para obras filantrópicas o públicas en los pueblos de origen, es compensado por una cantidad similar por parte de cada uno de los gobiernos: federal, estatal y municipal de México.

- Respetar el estatus de exentos de impuestos de la suma total de los pagos de los migrantes de retorno y crear programas de crédito que igualen las inversiones de estos fondos en empresas productivas.

- Vigilar activamente su lado de la frontera, para evitar intentos posteriores de cruce de la frontera fuera del programa legal de fuerza de trabajo. 
México no es un país pobre, sino de ingreso medio y su gobierno no es tan débil, como es común que se le presente en los medios de comunicación estadounidenses. El gobierno federal mexicano ha intervenido vigorosa y efectivamente en muchas instancias de conflictos internos y de desastres naturales; dirige una vigorosa política externa; y opera una completa red de cincuenta consulados en el lado estadounidense de la frontera, con una variedad de programas útiles para sus expatriados. El enorme reto de combatir el tráfico de drogas ha hecho parecer a este gobierno menos efectivo de lo que realmente es. Si la migración se redefine como un programa bilateral de administración de fuerza de trabajo, habrá de ser muy capaz de cumplir con su lado del convenio.

Las medidas propuestas tendrían las siguientes ventajas mutuas:

- Proporcionar una fuerza de trabajo confiable a la agricultura y a otras industrias de mano de obra intensiva en Estados Unidos, al tiempo que se elimina la actual explotación de los trabajadores migrantes.

- Facilitar la organización de la fuerza de trabajo migrante, por parte de los sindicatos, ya que el temor de las represiones a los patrones y la deportación se eliminarían de manera efectiva.

- Hacer a los trabajadores mexicanos menos competitivos, dado que su vulnerabilidad ante los abusos de los empleos se reduciría a través de la sindicalización y el recurso a las cortes. Esto habrá de presionar los salarios hacia el alta, haciendo que los trabajos normales sean más atractivos al menos para algunos trabajadores nacionales.

- Conservar en su lugar de origen a las familias de los migrantes, eliminando la carga social de una población permanentemente empobrecida y la probabilidad de una asimilación descendiente en la segunda generación.

- Evitar el despoblamiento de los pueblos y regiones de origen de los migrantes, al mismo tiempo que se promueve la inversión productiva de los ahorros de los migrantes a su regreso.

- Generar un programa ordenado para la migración permanente y el establecimiento. Las solicitudes de residencia permanente en Estados Unidos se reducirán por medio de incentivos reales para el retorno y la selectividad de los migrantes permanentes se asegurará a través de sus registros de trabajo y conducta general, mientras estén con un estatus temporal.

Si transcurridos de tres a cinco años, el programa bilateral deriva en los resultados esperados, puede ampliarse a otros países exportadores de mano de obra en Centroamérica. Esta ampliación no debe hacerse, sin embargo, de una sola vez, dado que es imperativo restaurar primero el carácter cíclico y la legalidad del sistema migratorio entre México y Estados Unidos.

Los críticos que argumentan que los migrantes "despojan a los 
ciudadanos de sus empleos", que son difíciles de sindicalizar, o que un programa temporal de fuerza de trabajo crearía condiciones "similares a la esclavitud" deberían esperar la carga de la prueba, mostrando cómo las circunstancias actuales tienen alguna diferencia respecto a lo que ellos denuncian, o cómo éstas superan al programa propuesto. Estas críticas son especialmente inadecuadas, ya que tienden a proyectar hacia el futuro las condiciones que ya existen, precisamente por que no se ha creado un programa de administración de la fuerza de trabajo para superarlas.

A pesar de sus debilidades, el viejo Programa Brasero mexicano era probablemente superior a lo que siguió. Este programa se terminó con los argumentos de que era "explotador" y "despojaba de sus empleos a los trabajadores estadounidenses". El flujo clandestino que siguió al cierre del programa recreó esas condiciones y las hizo aún peores. Los empleos para los trabajadores no autorizados se hicieron más explotadores y los patrones se acostumbraron más a preferir la fuerza de trabajo extranjera, dócil y barata, sobre los trabajadores nativos. La calamitosa situación en la que vivimos en la actualidad es un resultado directo del cierre del Programa Brasero, sin que se haya sustituido por una alternativa nacional.

Los liberales pueden aprender de esta experiencia y no permitir que sus preocupaciones idealistas los alejen de lo que es viable y de lo que es correcto. En un mundo ideal, los mexicanos y otros trabajadores extranjeros tendrían oportunidades decentes de empleo en sus lugares de origen y no tendrían que emigrar; las firmas estadounidenses contratarían a trabajadores nativos y les pagarían salarios altos con amplias prestaciones. No es así como funcionan las cosas en el mundo real y la lucha para cumplir estos ideales estorba a las soluciones prácticas y viables. Un programa de fuerza de trabajo temporal no es lo ideal; es simplemente la mejor opción en la presente realidad y si se le maneja adecuadamente, acabará con las quejas acerca de las "fronteras quebrantadas" y funcionará en interés tanto de los trabajadores como de los patrones y en ambos lados de la frontera. 